\title{
Stevia rebaudiana Bertoni Leaves Extract as a Nutraceutical with Hypoglycemic Activity in Diabetic Rats
}

\author{
Keri Lestari ${ }^{1,2 *}$, Abdurahman Ridho ${ }^{1}$, Nuning Nurcayani ${ }^{3}$, Zelika Mega Ramadhania ${ }^{4}$, \\ Melisa Intan Barliana ${ }^{2,4}$ \\ ${ }^{1}$ Department of Pharmacology and Clinical Pharmacy, Faculty of Pharmacy, Universitas Padjadjaran, Jl. Km 21.5 Bandung-Sumedang, \\ Jatinangor, Indonesia \\ ${ }^{2}$ Center of Excellence in Higher Education for Pharmaceutical Care Innovation, Universitas Padjadjaran, Indonesia \\ ${ }^{3}$ Darya Padma Enoes Company, Jawa Barat, Indonesia \\ ${ }^{4}$ Department of Biological Pharmacy, Faculty of Pharmacy, Universitas Padjadjaran, Jl. Km 21.5 Bandung-Sumedang, Jatinangor, Indonesia \\ *Corresponding author. E-mail: lestarikd@unpad.ac.id
}

Received date: Dec 18, 2018; Revised date: Feb 13, 2019; Accepted date: Feb 22, 2019

\section{Abstract}

B

ACKGROUND: The prevalence of diabetes mellitus is growing every year, including in Indonesia. Medicinal herbs were used empirically for lowering blood glucose. One of potential herb to have hypoglycemic activity is Stevia. Stevia rebaudiana Bertoni leaves contain stevoside, a natural, low-calorie sweetener that is 300 times sweeter than saccharose. In this study, we aimed to explore the hypoglycemic activity of $S$. rebaudiana Bertoni leaves extract in a rat model of type 2 diabetes mellitus (T2DM).

METHODS: Male Wistar rats were feed high-fat, highcarbohydrate feed and sugar solution for 74 days to induce a diabetic rat model. The animals were then divided into five groups consisting of a negative control group treated with 2\% Pulvis Gom Arabicum; a positive control group treated with Metformin $45 \mathrm{mg} / \mathrm{kg}$ body weight (BW); and three test groups treated with aqueous extract of $S$. rebaudiana Bertoni leaves at doses of 3.125, 6.25 and $12.5 \mathrm{mg} / \mathrm{kg} \mathrm{BW}$ for 36 days. Blood glucose was measured on days 14, 28 and 36 .

RESULTS: The results showed that blood glucose levels over 36 days were significantly ( $p=0.043$ ) lower in the group treated with $S$. rebaudiana Bertoni leaves extract. Further Newman-Keuls analysis suggested that the hypoglycemic activity of $S$. rebaudiana Bertoni leaves extract was dosedependent.

CONCLUSION: Our results indicate that $S$. rebaudiana Bertoni leaves extract has a potential role as a hypoglycemic agent in the treatment of T2DM.

KEYWORDS: Stevia rebaudiana Bertoni, nutraceuticals, hypoglycemic, diabetic rats

Indones Biomed J. 2019; 11(2): 182-7

\section{Introduction}

Type 2 Diabetes Mellitus (T2DM) is metabolic disorder that punctuated by insulin resistance. Some factors may trigger T2DM such as consumption of high calorie intake, obesity, sedentary lifestyle, as well as genetic. $(1,2)$ More than $80 \%$ of all patients with diabetes are T2DM. Epidemiological research in developed countries showed that due to high older population structure and high rates of obesity, the incidence and prevalence of T2DM are

increasing. According to World Health Organization estimation, Indonesia has the fourth largest diabetic population in the world after India, China, and the United States.(3)

Indonesia is the third most bio-diverse country in Asia, after India and China, possessing rich resources of medicinal herbs with the potential to act as hypoglycemic agents. The extract of Stevia rebaudiana Bertoni (S. rebaudiana; Asteraceae), a herbaceous plant, has been used for many years in the treatment of diabetes among indigenous people of Paraguay and Brazil.(4,5) 
S. rebaudiana Bertoni leaves contain stevioside, a natural, low-calorie sweetener that is 300 times sweeter than saccharose. A number of recent studies revealed that consumption of $S$. rebaudiana Bertoni can lower the plasma glucose level.(5-7) Aquatic extract of S. rebaudiana Bertoni can stimulate insulin secretion, sensitivity by acting directly on pancreatic beta cells, and showed antioxidant properties. $(4,8,9)$ Furthermore, stevioside and steviol that extracted from $S$. rebaudiana Bertoni showed to increase expresion of glucose transporter type 4 (GLUT4) gene and protein, and also glucose uptake in cells.(10)

Previous studies started the extraction of stevioside from S. rebaudiana Bertoni leaves were using water- or alcohol-based extraction and followed by purification, filtration, and identification by high performance liquid chromatography (HPLC), nuclear magnetic resonance (NMR), and mass spectrometry (MS).(11) Stevioside and other 20 compounds that isolated from S. rebaudiana Bertoni leaves were extracted from hot water.(12)

A beverage prepared from $S$. rebaudiana Bertoni leaves caused a $35 \%$ reduction in blood glucose in humans. This indicates that $S$. rebaudiana Bertoni leaves extract possesses blood-glucose-lowering properties and may be a potential treatment for diabetes mellitus.(13-15) The aim of this study was to determine the hypoglycemic activity of $S$. rebaudiana Bertoni leaves aqueous extract in a rat model of T2DM.

\section{Methods}

\section{Plant Material}

S. rebaudiana Bertoni leaves were collected from Manoko Lembang, Jawa Barat, Indonesia. Plants were identified in the Plant Taxonomy Laboratory, Department of Biology, Faculty of Natural Sciences, Universitas Padjadjaran, with the identification number $560 / \mathrm{HB} / \mathrm{II} / 2016$. The result of the identification process indicated that the plant samples used in this study were $S$. rebaudiana Bertoni species from the Asteraceae family. $S$. rebaudiana Bertoni leaves were cleaned and dried at room temperature then chopped into small slices. The small leaf slices were extracted with distilled water and freeze dried. The freeze-dried $S$. rebaudiana Bertoni leaves was stored at $4^{\circ} \mathrm{C}$ until used in assays.

\section{Diabetic Rat Model Preparation}

Male Wistar rats 2-3 months old and weighing approximately 150-250 $\mathrm{g}$ were used in the model. All rats were acclimatized to the new environment for 1 week prior to treatment, housed under standard laboratory conditions with a 12:12 h light/dark cycle, fed in pellet feed and water ad libitum. Rats were divided into two groups; normal group and diabetic rats groups. Normal rat group were fed with commercially available rat standard pellet diet and diabetic rat groups were fed with high-fat, high-carbohydrate pellet diet that feed $20 \mathrm{~g} / \mathrm{rat} / \mathrm{day}$ and $10 \%$ sugar solution for 74 days to induce T2DM (without aqueous extract of $S$. rebaudiana Bertoni leaves). A fasting blood glucose level of $\geq 110 \mathrm{mg} /$ $\mathrm{dL}$ was the criterion for T2DM in high fat and high fructose diet fed rat. $(16,17)$ Blood glucose levels were measured by using glucometer strips.

\section{Hypoglycemic Activity of $S$. rebaudiana Bertoni leaves Extract in Diabetic Rats}

Diabetic rats were divided into five groups (each group consisting of five rats) as follows: the negative control group was treated with 2\% Pulvis Gom Arabicum (PGA), the positive control group was treated with Metformin $45 \mathrm{mg} / \mathrm{kg}$ body weight (BW) in 2\% PGA. The three test groups were treated with freeze-dried aqueous extract of $S$. rebaudiana Bertoni leaves in 2\% PGA at doses of $3.125 \mathrm{mg} /$ kg BW (Group 1), $6.25 \mathrm{mg} / \mathrm{kg} \mathrm{BW}$ (Group 2), and $12.5 \mathrm{mg} /$ kg BW (Group 3) once a day for 36 days. During treatment with the aqueous extract of $S$. rebaudiana Bertoni leaves, all the animal groups were fed high-fat, high-carbohydrate feed and 10\% sugar solution. Blood samples were taken by cutting the tip of the rat's tail, and blood glucose levels were measured on days $0,14,28$ and 36 after treatment with aqueous extract of $S$. rebaudiana Bertoni leaves. Before blood sampling, the rats were fasted for 8-12 hours, to eliminate interference of consumed food with blood glucose levels. BW was also measured on day 0, 14, 28 and 42 after treatment.

All procedures involving animal subjects were performed in accordance with the institutional and/ or national research ethical standards and approved by Universitas Padjadjaran Medical Research Ethics Committee number 1150/UN6C1.3.2/KEPK/PN/2016.

\section{Statistical Analysis}

The data were presented in mean $\pm \mathrm{SD}$. The statistical significance were analyzed using paired Student's t-tests.

\section{Results}

\section{T2DM Rat Model Induction}

The rat model of T2DM was induced by high-fat, highcarbohydrate feed and 10\% sugar solution. Fasting blood 


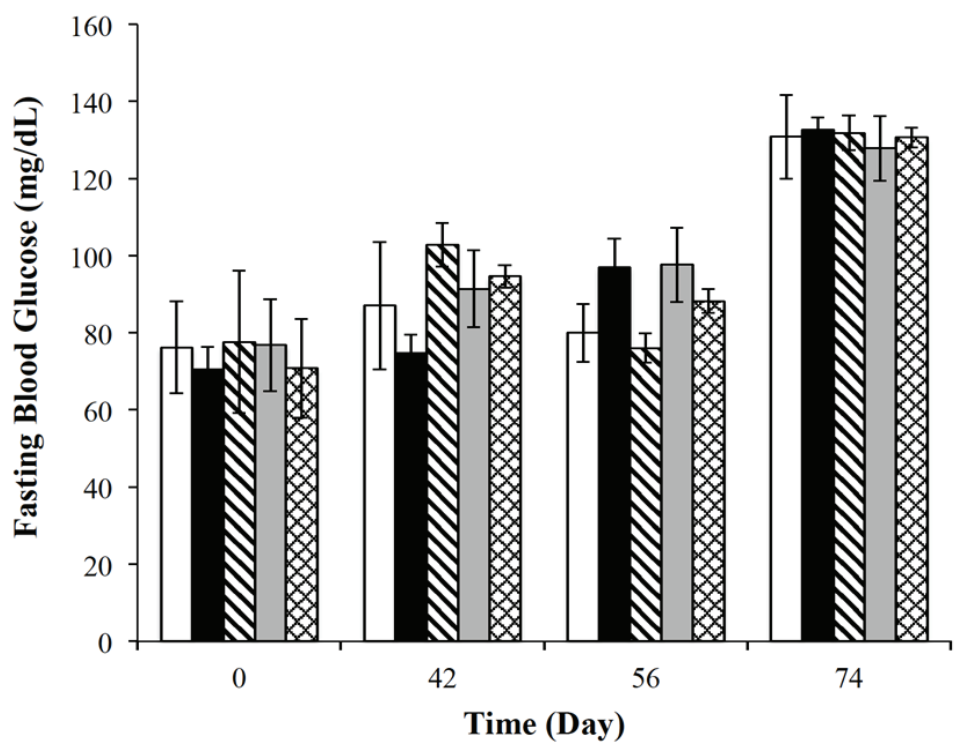

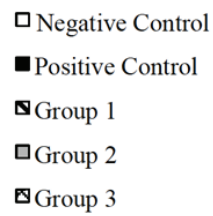

Figure 1. The average of fasting blood glucose level in induction of T2DM. All the rat groups were fed by high fat-high carbohydrate feed and 10\% sugar solution until blood glucose level $\geq 110 \mathrm{mg} / \mathrm{dL}$ for $0,42,56$ and 74 days. glucose was increased slightly at days 42 and 56 and met the criteria for T2DM ( $\geq 110 \mathrm{mg} / \mathrm{dL}$ ) at day 74 (Figure 1). At day 74, the T2DM rat model had an average fasting blood glucose level was $129.8 \pm 5.9 \mathrm{mg} / \mathrm{dL}$.

The results showed that high-fat, high-carbohydrate feed and $10 \%$ sugar solution produced a T2DM rat model similar to a sedentary lifestyle as a factor for T2DM in humans. Fasting blood glucose levels were increased significantly in all groups at day 74 compared with day 0 $(p \leq 0.05)$ (Table 1$)$. The BWs of T2DM model rats were measured every 2 weeks following induction of T2DM. The BWs of all groups were increased by induction with highfat, high-carbohydrate feeding and 10\% sugar solution.

\section{Hypoglycemic Activity of $S$. rebaudiana Bertoni leaves}

Evaluation of the hypoglycemic activity of freeze-dried $S$. rebaudiana Bertoni leaves extract was carried out to determine the potential of the extract to lower blood glucose levels effectively. The mean fasting blood glucose levels of rats during the treatment were calculated (Figure 2, Table 2). Day 0 refers to day 0 of $S$. rebaudiana Bertoni

Table 1. The $p$-value of student's t-test on fasting blood glucose levels of high fat, high and $10 \%$ sucrose-induced rat in day 74 compared to day 0 .

\begin{tabular}{lc}
\hline \multicolumn{1}{c}{ Group } & $\boldsymbol{p}$-value \\
\hline $\mathrm{C}(-)$ & $\mathbf{0 . 0 0 0 1}$ \\
$\mathrm{C}(+)$ & $\mathbf{0 . 0 0 0 0}$ \\
Group 1 & $\mathbf{0 . 0 0 0 2}$ \\
Group 2 & $\mathbf{0 . 0 0 0 1}$ \\
Group 3 & $\mathbf{0 . 0 2 4 0}$ \\
\hline
\end{tabular}

leaves extract-treatment, which is day 74 after induction. Treatment with $S$. rebaudiana Bertoni leaves extract for 5 weeks decreased fasting blood glucose levels in a timeand dose-dependent manner. The higher the dose of $S$. rebaudiana Bertoni leaves extract, the higher the observed blood-glucose-lowering activity.

In the positive control group (Metformin) and the test group ( $S$. rebaudiana Bertoni leaves aqueous extract), at several dose levels, the mean fasting blood glucose level was decreased by $43.33 \%$ and $38.6 \%$, respectively. Statistical analysis using analysis of variance showed a significant difference with each treatment in the parameter measured at $\alpha=0.05$. This means that each treatment had a significant blood-glucose-lowering effect at the $95 \%$ confidence level (Table 3). Treatment with S. rebaudiana Bertoni leaves extract significantly decreased fasting blood glucose levels at the $36^{\text {th }}$ day in the Metformin group $(p=0.042)$ and Group $3(p=0.043)$ rats according to analysis by Student's t-test (Figure 2).

BW increases in the T2DM rat model after induction and treatment with $S$. rebaudiana Bertoni leaves extract are shown in Figure 3. From the graph shown, it can be observed that after a total 116 days of high-calorie sugar induction and treatment with $S$. rebaudiana Bertoni leaves extract, all animals in three test groups and two control groups had gained BW.

\section{Discussion}

In all groups of rats, T2DM was induced by high-fat, highcarbohydrate feeding and 10\% sugar solution, mimicking the sedentary lifestyle that stimulates T2DM development 


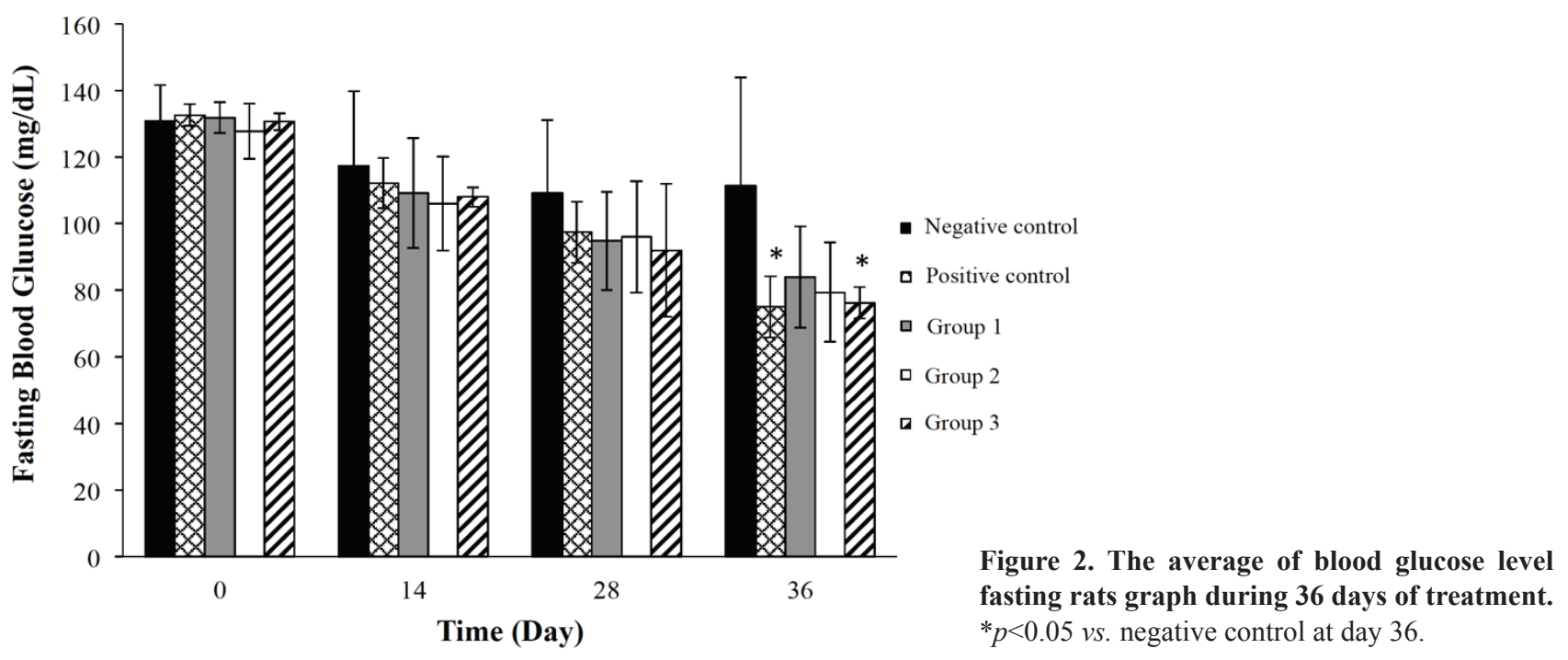

in humans. In the present study, we did not use alloxan or streptozotocin, because they destroy the pancreatic $\beta$ cells and mimic type 1 diabetes mellitus.(18-20) Although high fat and high carbohydrate feed induced T2DM showed some limitation, but these induction established suitable condition for obesity and T2DM in etiology, pathology and treatment. (21) Our previous study also using high fat diet-fed mouse in safrol-free nutmeg seed extract to establish T2DM mouse model.(22) One of limitation of present study that insulin level was not measured during the treatment and to confirm T2DM progression in diabetic rats.

High-fat and high-carbohydrate diets will increase the fat level in the blood, stimulate fat metabolism, and produce reactive oxygen species (ROS) in the blood and adipose cells. Increasing the production of ROS in adipose cells will disturb the balance of redox reactions. Furthermore,

Table 2. The average of fasting glucose levels of rats during 36 days of treatment.

\begin{tabular}{lcccc}
\hline \multirow{2}{*}{ Group } & \multicolumn{4}{c}{ The Average of Fasting Glucose Levels of Rats } \\
& \multicolumn{4}{c}{ (mg/dL) } \\
\cline { 2 - 5 } & Day 0 & Day 14 & Day 28 & Day 36 \\
\hline C(-) & $126.2 \pm 10.92$ & $117.4 \pm 22.45$ & $109.2 \pm 21.80$ & $111.4 \pm 32.42$ \\
C(+) & $132.6 \pm 3.29$ & $112.2 \pm 7.60$ & $97.4 \pm 9.18$ & $75 \pm 9.22$ \\
Group 1 & $131.8 \pm 4.55$ & $109.2 \pm 16.57$ & $94.8 \pm 14.79$ & $84 \pm 15.25$ \\
Group 2 & $127.8 \pm 8.35$ & $106 \pm 14.14$ & $96 \pm 16.72$ & $79.4 \pm 14.88$ \\
Group 3 & $130.6 \pm 2.51$ & $108 \pm 2.92$ & $92 \pm 19.99$ & $76.2 \pm 14.14$ \\
\hline
\end{tabular}

Day 0: The blood glucose levels of rats before treated; $\mathrm{C}(-)$ : Negative Control (PGA 2\%); C(+): Positive Control (PGA 2\% + Metformin $45 \mathrm{mg} / \mathrm{g} \mathrm{BW}$ ); Group 1: PGA 2\% + stevia water extract with a dose of $3.125 \mathrm{mg} / \mathrm{kg} \mathrm{BW}$; Group 2: PGA 2\% + stevia water extract with a dose of $6.25 \mathrm{mg} / \mathrm{kg} \mathrm{BW}$; Group 3: PGA 2\% + stevia water extract with a dose of $12.5 \mathrm{mg} / \mathrm{kg} \mathrm{BW}$. it will decrease the amount of antioxidant enzymes in the circulation, producing oxidative stress. $(23,24)$ Hence, glucose uptake in muscle cells and fat cells will be inhibited and insulin secretion by pancreatic $\beta$ cells will be decreased. Oxidative stress also directly affects vascular membranes and plays a pivotal role in the pathophysiology of T2DM and atherosclerosis.(25)

S. rebaudiana Bertoni as a herbal plant shows promising activity as a T2DM therapy or supplement. In the present study, we observed that freeze-dried S. rebaudiana Bertoni leaves extract decreased the blood glucose level in a T2DM rat model at a small dose $(12.5 \mathrm{mg} / \mathrm{kg} \mathrm{BW})$. With high-fat, high-carbohydrate and 10\% sugar solution feeding, the BWs of $S$. rebaudiana Bertoni leaves extracttreated rat groups was increased, but the blood glucose levels were decreased significantly. This result indicates that S. rebaudiana Bertoni may control blood glucose levels in a T2DM rat model.

In previous studies, $400 \mathrm{mg} / \mathrm{kg} \mathrm{BW}$ of aquatic extract of S. rebaudiana Bertoni leaves was observed to lower fasting blood glucose, triglycerides, and hepatic parameters after 28 days of treatment.(8) A methanol extract of S. rebaudiana Bertoni root treatment in diabetic rats was observed to lower blood glucose levels, increase the hepatic glycogen content, and maintain BW and lipid-profile parameters in the near-normal range.(9) A study of S. rebaudiana Bertoni as a sweet herb ( $1 \mathrm{~g} \mathrm{~S}$. rebaudiana Bertoni leaves powder) in T2DM subjects significantly lowered fasting and postprandial blood glucose levels, triglycerides, and very lowdensity lipoprotein cholesterol (VLDL-C) levels.(15)

The sweet taste of $S$. rebaudiana Bertoni comes from stevioside which is a glycosidic diterpenes, that has 300 times sweeter than sucrose with zero calorie. $(26,27)$ 
Table 3. The $p$-value of Student's t- test on fasting blood glucose levels of diabetic rat after treatment with $S$. rebaudiana Bertoni extract in day 36 compare to negative control group.

\begin{tabular}{lccc}
\hline \multirow{2}{*}{ Groups } & \multicolumn{3}{c}{$p$-value } \\
\cline { 2 - 4 } & Day 14 & Day 28 & Day 36 \\
\hline C (+) & 0.6368 & 0.297 & $0.0422 *$ \\
Group 1 & 0.5295 & 0.2564 & 0.1256 \\
Group 2 & 0.3648 & 0.314 & 0.0798 \\
Group 3 & 0.3802 & 0.2297 & $0.0431 *$ \\
\hline
\end{tabular}

*significant $p<0.05$.

Mechanistically, S. rebaudiana Bertoni lowers blood glucose levels by increasing insulin secretion and decreasing glucagon secretion in $\alpha$-pancreatic cells. Stevioside, which is the major compound of $S$. rebaudiana Bertoni, has the effect of stimulating insulin secretion and increasing insulin sensitivity by acting directly on pancreatic beta cells. $(28,29)$ Another study showed that $S$. rebaudiana Bertoni extract increased the expression of peroxisome proliferatoractivated receptor- $\gamma$ (PPAR $\gamma$ ) and insulin mRNA.(8) PPAR $\gamma$ plays an important role in maintaining glucose metabolism by stimulating glucokinase and GLUT2 in the pancreas and liver.(30) By increasing the expression of PPAR $\gamma$ and GLUT4, stevioside will enhance the glucose uptake into the cells, thereby glucose in blood were metabolized and resulting in lowering blood glucose level.(30)

The finding that the aqueous extract of $S$. rebaudiana Bertoni could increase the $\mathrm{BW}$ of a rat animal model in this study could be very valuable to the supplementary use of S. rebaudiana Bertoni, since most diabetic patients struggle with significant BW loss due to strict limitation of the blood glucose level. In contrast, another study that used birds as an animal model has proven that $S$. rebaudiana Bertoni leaves used as a poultry food supplement could contribute to increasing the abdominal fat content. The mechanism by which $S$. rebaudiana Bertoni acts to increase broiler BW is by it component stevioside increasing glucose intake from the vascular blood, which is later converted to fat and stored in the abdomen of test animals.(31)

The insulin resistance caused high blood glucose level in diabetic subjects can decrease BW through gluconeogenesis in liver which are producing endogenous glucose from fat. This condition showed a metabolic disturbance.(32) S. rebaudiana Bertoni consumption increasing insulin secretion, increase insulin sensitivity, and decreasing glucagon secretion in $\alpha$-pancreatic cells. Therefore, gluconeogenesis is decreased, lipolysis is decreased or stops. Hence, S. rebaudiana Bertoni consumption will improve the metabolism and homeostatic BW can be arisen. However, further studies on how $S$. rebaudiana Bertoni could increase $\mathrm{BW}$ in a rat model should be performed to clarify these results.

\section{Conclusion}

Aqueous extract of $S$. rebaudiana Bertoni leaves at doses of $3.125 \mathrm{mg} / \mathrm{kg} \mathrm{BW}, 6.25 \mathrm{mg} / \mathrm{kg} \mathrm{BW}$ and $12.5 \mathrm{mg} / \mathrm{kg} \mathrm{BW}$ can lower blood glucose levels significantly. The percentage decrease in blood glucose levels was correlated with the given dose, and the greatest decrease in the blood was obtained from a dose of $12.5 \mathrm{mg} / \mathrm{kg}$ BW of $38.6 \%$ in a T2DM rat model. Based on the analysis, stevia extract has potential dose-dependent hypoglycemic activity.

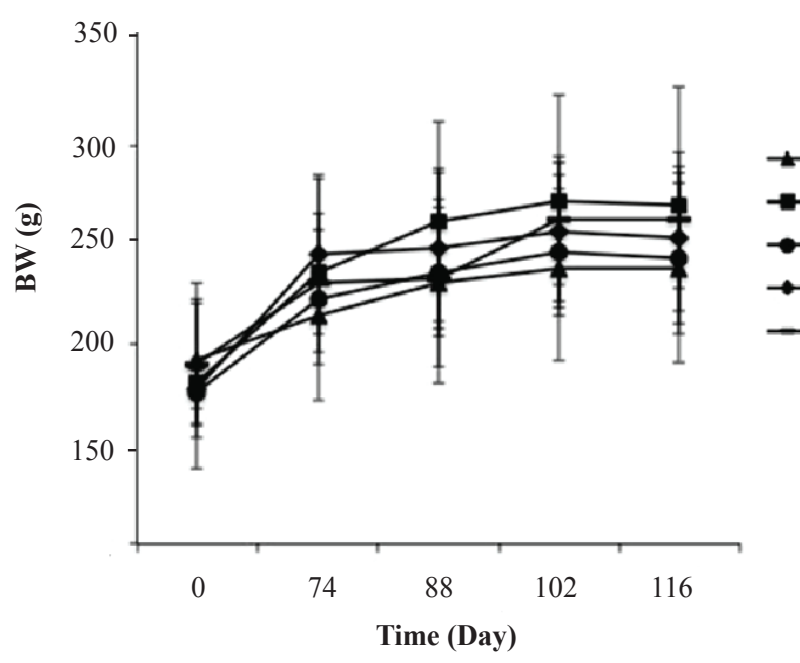

Figure 3. Increasing BW in T2DM-rats model after induction and treatment of $S$. rebaudiana Bertoni extract. 


\section{References}

1. Kahn SE, Cooper ME, Del Prato S. Pathophysiology and treatment of type 2 diabetes: perspectives on the past, present, and future. Lancet. 2014; 383:1068-83.

2. Hussain Y, Jain SK, Samaiya PK. Short-term westernized (HFFD) diet fed in adolescent rats: Effect on glucose homeostasis, hippocampal insulin signaling, apoptosis and related cognitive and recognition memory function. Behav Brain Res. 2019; 361: 113-21.

3. Shaw JE, Sicree RA, Zimmet PZ. Global estimates of the prevalence of diabetes for 2010 and 2030. Diabetes Res Clin Pract. 2010; 87: 4-14.

4. Goyal SK, Samsher, Goyal RK. Stevia (Stevia rebaudiana) a biosweetener: a review. Int J Food Sci Nutr. 2010; 61: 1-10.

5. Ferrazzano GF, Cantile T, Alcidi B, Coda M, Ingenito A, Zarrelli A, et al. Is Stevia rebaudiana Bertoni a non cariogenic sweetener? A review. Molecules. 2015;21:E38. doi: 10.3390/molecules21010038.

6. Lemus-Mondaca R, Vega-Galvez A, Zura-Bravo L, Ah-Hen K. Stevia rebaudiana Bertoni, source of a high-potency natural sweetener: A comprehensive review on the biochemical, nutritional and functional aspects. Food Chem. 2012; 132: 1121-32.

7. Karim MZ, Uesugi D, Nakayama N, Hossain MM, Ishihara K, Hamada H. Identification of stevioside using tissue culture-derived stevia (Stevia rebaudiana) leaves. Biochem Insights. 2015; 8(Suppl 2): 33-7.

8. Assaei R, Mokarram P, Dastghaib S, Darbandi S, Darbandi M, Zal F, et al. Hypoglycemic effect of aquatic extract of stevia in pancreas of diabetic rats: PPARgamma-dependent regulation or antioxidant potential. Avicenna J Med Biotechnol. 2016; 8: 65-74.

9. Sing S, Garg V. Antidiabetic, antidyslipidymic and antioxidative potential of methanolic root extract of Stevia rebaudiana (Bertoni) on alloxan induced diabetic mice. J Pharm Pharm Sci. 2014; 3: 1859-72.

10. Bhasker S, Madhav H, Chinnamma M. Molecular evidence of insulinomimetic property exhibited by steviol and stevioside in diabetes induced L6 and 3T3L1 cells. Phytomedicine. 2015; 22: 1037-44.

11. Ceunen S, Geuns JM. Steviol glycosides: chemical diversity, metabolism, and function. J Nat Prod. 2013; 76: 1201-28.

12. Ohta M, Sasa S, Inoue $\mathrm{A}$, Tamai $\mathrm{T}$, Fujita $\mathrm{I}$, Morita $\mathrm{K}$, et al. Characterization of novel steviol glycoside from leaves of Stevia rebaudiana Morita. J Appl Glycosci. 2010; 57: 199-209.

13. Chaves G, Britez N, Oviedo G, Gonzalez G, Italiano C, Blanes M, et al. Heavy drinkers of Ilex paraguariensis beverages show lower lipid profiles but higher body weight. Phytother Res. 2018; 32: 1030-8.

14. Mayasari NR, Susetyowati, Wahyuningsih MSH, Probosuseno. Antidiabetic effect of rosella-stevia tea on prediabetic women in Yogyakarta, Indonesia. J Am Coll Nutr. 2018; 37: 373-9.

15. Ritu M, Nandini J. Nutritional composition of Stevia rebaudiana, a sweet herb, and its hypoglycaemic and hypolipidaemic effect on patients with non-insulin dependent diabetes mellitus. J Sci Food Agric. 2016; 96: 4231-4.

16. Vasilescu R. Metabolic syndrome in clinical practice considerations on diagnostic criteria and prevalence. Terapeutica. 2011; XV: 93-7.

17. Lozano I, Van der Werf R, Bietiger W, Seyfritz E, Peronet C, Pinget $\mathrm{M}$, et al. High-fructose and high-fat diet-induced disorders in rats: impact on diabetes risk, hepatic and vascular complications. Nutr Metab. 2016; 13: 15. doi: 10.1186/s12986-016-0074-1.
18. Zhuo J, Zeng Q, Cai D, Zeng X, Chen Y, Gan H, et al. Evaluation of type 2 diabetic mellitus animal models via interactions between insulin and mitogenactivated protein kinase signaling pathways induced by a high fat and sugar diet and streptozotocin. Mol Med Rep. 2018;17: 5132-42.

19. Fatih Aydin A, Kucukgergin C, Bingul I, Dogan-Ekici I, DogruAbbasoglu S, Uysal M. Effect of carnosine on renal function, oxidation and glycation products in the kidneys of high-fat diet/ streptozotocin-induced diabetic rats. Exp Clin Endocrinol Diabetes. 2017; 125: 282-9.

20. Liu XY, Liu FC, Deng CY, Zhang MZ, Yang M, Xiao DZ, et al. Left ventricular deformation associated with cardiomyocyte $\mathrm{Ca}(2+)$ transients delay in early stage of low-dose of STZ and high-fat diet induced type 2 diabetic rats. BMC Cardiovasc disor. 2016; 16: 41. doi: 10.1186/s12872-016-0220-8.

21. Heydemann A. An overview of murine high fat diet as a model for type 2 diabetes mellitus. J Diabetes Res. 2016; 2016: 2902351. doi: 10.1155/2016/2902351.

22. Lestari K, Diantini A, Barliana MI, Achmad TH, Subarnas A, Mutakin, et al. Potential natural dual agonist PPAR $\alpha / \gamma$-induced antidiabetic and antidyslipidemic properties of safrole-free nutmeg seed (Myristica fragrans Houtt) extract. Nat Prod J. 2019; 9: 248-53.

23. Maslov LN, Naryzhnaya NV, Boshchenko AA, Popov SV, Ivanov VV, Oeltgen PR. Is oxidative stress of adipocytes a cause or a consequence of the metabolic syndrome? J Clin Transl Endocrinol. 2019; 15: 1-5.

24. Paglialunga S, Ludzki A, Root-McCaig J, Holloway GP. In adipose tissue, increased mitochondrial emission of reactive oxygen species is important for short-term high-fat diet-induced insulin resistance in mice. Diabetologia. 2015; 58: 1071-80.

25. Odegaard AO, Jacobs DR, Jr., Sanchez OA, Goff DC, Jr., Reiner AP, Gross MD. Oxidative stress, inflammation, endothelial dysfunction and incidence of type 2 diabetes. Cardiovasc Diabetol. 2016; 15: 51. doi: 10.1186/s12933-016-0369-6.

26. Kobus-Moryson M, Gramza-Michalowska A. Directions on the use of stevia leaves (Stevia Rebauidana) as an additive in food products. Acta Sci Pol Technol Aliment. 2015; 14: 5-13.

27. Samuel P, Ayoob KT, Magnuson BA, Wolwer-Rieck U, Jeppesen PB, Rogers PJ, et al. Stevia leaf to stevia sweetener: exploring its science, benefits, and future potential. J Nutr. 2018; 148: 1186S-205S.

28. Carrera-Lanestosa A, Moguel-Ordonez Y, Segura-Campos M. Stevia rebaudiana Bertoni: A natural alternative for treating diseases associated with metabolic syndrome. J Med Food. 2017; 20: 93343.

29. Piovan S, Pavanello A, Peixoto GML, Matiusso CCI, de Moraes AMP, Martins IP, et al. Stevia nonsweetener fraction displays an insulinotropic effect involving neurotransmission in pancreatic islets. Int J Endocrinol. 2018; 2018: 3189879. doi: 10.1155/2018/3189879.

30. Gupta D, Kono T, Evans-Molina C. The role of peroxisome proliferator-activated receptor gamma in pancreatic beta cell function and survival: therapeutic implications for the treatment of type 2 diabetes mellitus. Diabetes Obes Metab. 2010; 12: 103647.

31. Atteh JO, Onagbesan OM, Tona K, Decuypere E, Geuns JM, Buyse J. Evaluation of supplementary stevia (Stevia rebaudiana, bertoni) leaves and stevioside in broiler diets: effects on feed intake, nutrient metabolism, blood parameters and growth performance. J Anim Physiol Anim Nutr. 2008; 92: 640-9.

32. Ahn YH. A journey to understand glucose homeostasis: starting from rat glucose transporter type 2 promoter cloning to hyperglycemia. Diabetes Metab J. 2018; 42: 465-71. 